initially thought to represent the $4 p-$ syndrome. However, chromosome analysis failed to confirm this diagnosis and instead identified a normal male karyotype.

Review of published reports revealed four case reports $^{1-3}$ of phenotypically female infants with a 46,XY karyotype and other multiple congenital anomalies consistent with a diagnosis of SLO syndrome. Re-examination and comparison of the dysmorphic features found in our case and the previously reported cases (table) revealed several common features noted in SLO syndrome and substantiated this clinical diagnosis in the proband. Most significant in these cases was the normal female genitalia in the presence of a $\mathrm{Y}$ chromosome.

A wide spectrum of genital anomalies has been noted in SLO syndrome. Most commonly seen are cryptorchidism and hypospadias in the male. Cases of normal male phenotype as well as genital ambiguity have also been reported. ${ }^{4}$ However, it appears that in extreme SLO cases there may be complete failure of development of the male external genitalia with resulting normal female appearance. In fact, Lowry et al $^{5}$ have suggested that some severe cases of SLO syndrome with male pseudohermaphroditism may have been incorrectly identified as Meckel syndrome. Therefore, SLO syndrome should be included in the differential diagnosis of male pseudohermaphroditism, especially in the presence of other congenital anomalies.

The expert technical assistance of Vinnia Anderson and Dawn Bridges and the secretarial assistance of Shirley Gann are gratefully acknowledged and sincerely appreciated. This paper was supported in part by project $905, \mathrm{MCH}$, DHHS.

\section{References \\ ${ }^{1}$ Kretzer FL, Hittner HM, Mehta RS. Ocular manifestations of the Smith-Lemli-Opitz syndrome. Arch Ophthalmol 1981;99: 2000-6. \\ 2 Patterson K, Toomey KE, Chandra RS. Hirschsprung disease in a 46,XY phenotypic infant girl with Smith-Lemli-Opitz syn- drome. J Pediatr 1983;103:425-7. \\ ${ }^{3}$ Greene C, Pitts W, Rosenfeld R, Luzzatti L. Smith-Lemli-Opitz syndrome in two $46, \mathrm{XY}$ infants with female external genitalia. Clin Genet 1984:25:366-72. \\ 4 Johnson VP. Smith-Lemli-Opitz syndrome: review and report of two affected siblings. Z Kinderheilkd 1975;119:221-34. \\ 5 Lowry RB. Variability in the Smith-Lemli-Opitz syndrome: overlap with the Meckel syndrome. Am J Med Genet 1983;14:429-33.}

Correspondence and requests for reprints to Dr P R Scarbrough, Laboratory of Medical Genetics, University Station, Birmingham, Alabama 35294, USA.

\title{
Possible Waardenburg syndrome with gastrointestinal anomalies*
}

\author{
J NUTMAN $\dagger$, R STEINHERZ + , Y SIVAN $\dagger$, AND R M GOODMAN \\ †Department of Pediatrics A, Beilinson Medical Center, Petah Tiqva; and $\ddagger$ Department of Human Genetics, \\ Chaim Sheba Medical Center, Tel Hashomer, Israel.
}

SUMmaRY We describe a patient with possible Waardenburg syndrome associated with anal atresia and oesophageal atresia with tracheooesophageal fistula. Three other published cases with atretic gastrointestinal anomalies associated with the Waardenburg syndrome are reviewed. We conclude that the association between atretic lesions of the gastrointestinal tract and the Waardenburg syndrome may be a significant one.

Aganglionic megacolon (Hirschsprung disease) is known to be associated with the Waardenburg syndrome. ${ }^{1}$ In 1981 we called attention to the fact

*Supported in part by a grant to R M Goodman from the National Foundation for Jewish Genetic Disease, USA.

Received for publication 27 February 1984.

Revised version accepted for publication 18 February 1985 that other gastrointestinal anomalies may also be present in this syndrome, namely anal atresia. ${ }^{2}$ Recently we have seen another patient with possible Waardenburg syndrome who had anal atresia and oesophageal atresia with tracheo-oesophageal fistula. The purpose of this report is to present the findings of our patient and to discuss the significance of gastrointestinal anomalies in the Waardenburg syndrome.

\section{Case report}

A 1 year old female infant was referred to the Department of Pediatrics because of fever and wheezing bronchitis. The parents were Sephardi Jews originating from Libya and were not consanguineous. The child was born prematurely after 35 weeks' gestation by vertex delivery. Polyhydramnios was noted during pregnancy: Birth 
weight was $2450 \mathrm{~g}$. Shortly after birth she was diagnosed as suffering from oesophageal atresia with tracheo-oesophageal fistula and subsequently operated upon. She was discharged from the hospital at the age of 2 months and suffered from recurrent wheezing bronchitis and a few episodes of aspiration pneumonia due to gastro-oesophageal reflux. From birth she has suffered from constipation.
On physical examination the child appeared to be $\stackrel{\mathbb{P}}{+}$ alert with severe failure to thrive, weight $4500 \mathrm{~g}$, $\vec{F}$ length $60 \mathrm{~cm}$, and head circumference $42.5 \mathrm{~cm}$, all below the 3rd centile. The main physical findings included blepharophimosis with lateral displacement of the medial canthi and broad nasal root. The inter canthal distance was $2.8 \mathrm{~cm}$ (90th centile $\left.\mathrm{e}^{3}\right)$, the outer canthal distance was $6 \cdot 1 \mathrm{~cm}(3 \mathrm{rd}$ o

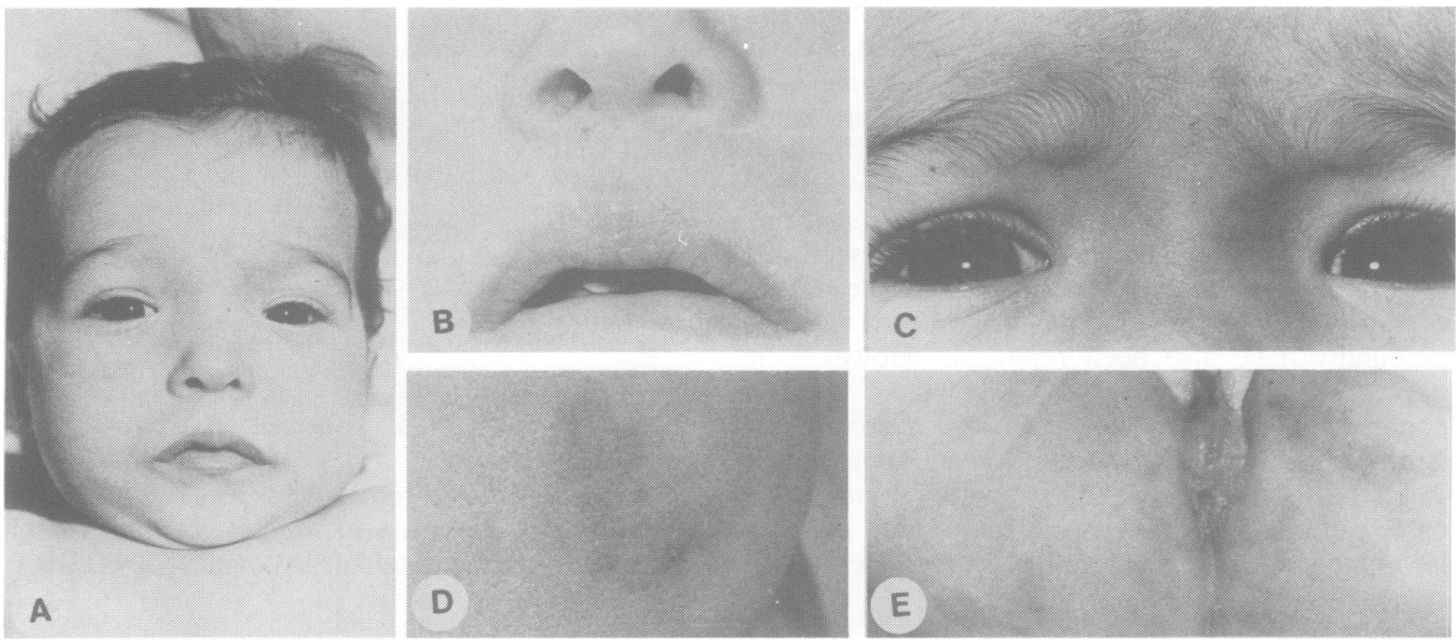

FIG 1 Patient's face showing blepharophimosis with lateral displacement of the medial canthi, hypoplastic nasal alae ( $A$ ), 'Cupid-bow' configuration of the upper lip (B), and broad nasal root with thickening of the medial aspect of the eyebrows $(C)$. $(D, E)$ Patient's abdomen and perineum showing areas of hyperpigmentation.
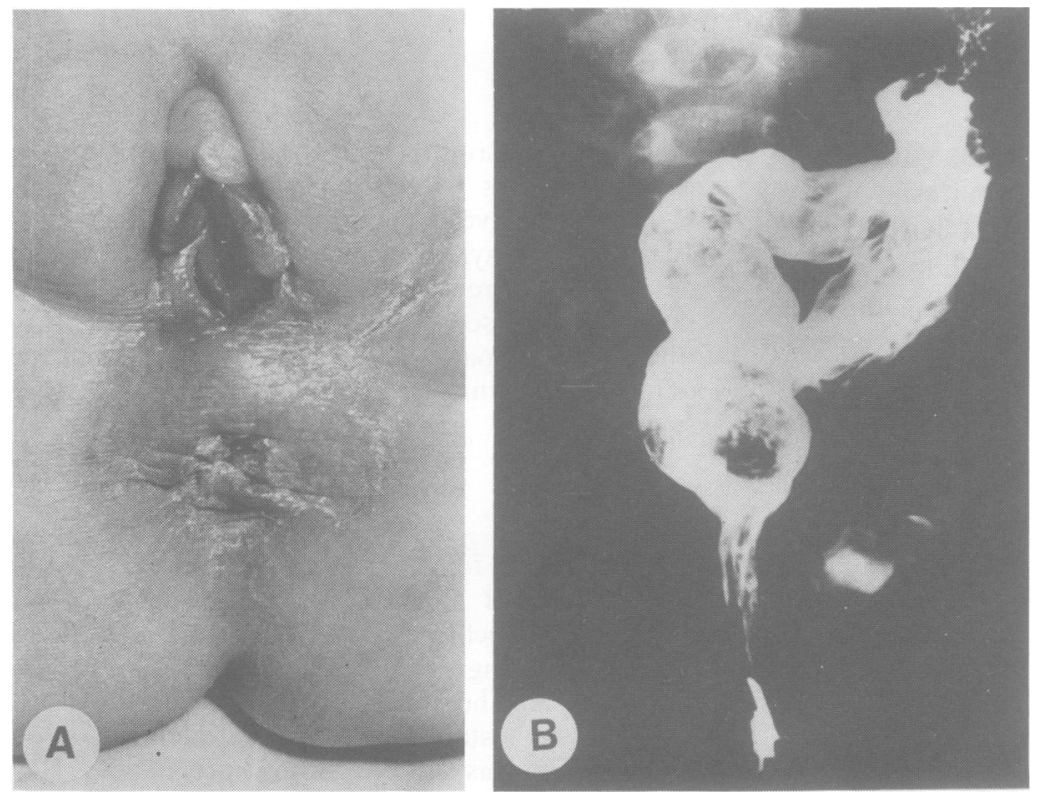

FIG 2 (A) Patient's perineum showing anal atresia with perineal fistula anterior to an anal dimple. (B) Barium enema showing anal atresia with perineal fistula. 
centile $\mathrm{e}^{3}$ ), and the interpupillary distance was $4.3 \mathrm{~cm}$ $\left(25\right.$ th centile $\left.{ }^{3}\right)$. There was a 'cupid-bow' configuration of the upper lip, and areas of vitiligo and hyperpigmentation on the trunk (fig 1) without evidence of depigmentation of the hair. Hyperelasticity of the skin was noted. The colour of her eyes was brown. Examination of the perineum revealed an imperforate anus and a perineal fistula situated $0.5 \mathrm{~cm}$ anteriorly. Barium enema and 'rectal' manometric studies confirmed the diagnosis (fig 2). She was treated with antibiotics and bronchodilators for her wheezing bronchitis and mineral oil for her constipation. After her recovery she was referred to the Department of Pediatric Surgery for evaluation of the gastro-oesophageal reflux and correction of the anal atresia.

\section{Discussion}

Possible Waardenburg syndrome was diagnosed in our patient on the basis of such classical features as blepharophimosis, lateral displacement of the medial canthi and lacrimal punctae, broad nasal root, hypoplastic nasal alae, and areas of skin hyperpigmentation and vitiligo. ${ }^{4}$ Our patient has all these features including the clinical impression of hearing loss. It should be noted that the child suffered from chronic otitis media which called for repeated tympanostomies. An audiogram was inconclusive because of the lack of cooperation due to the child's age. Thus, to exclude the hearing changes which could be attributed to sensorineural defect we conducted the BERA test. The response was within normal limits excluding nerve conduction defect. We therefore believe that the hearing loss merely reflected the state of chronic otitis media. Neither of the parents had any features that might be compatible with the Waardenburg syndrome. The mother had a hearing defect. Her audiogram showed a defect in air conduction in the right ear without impairment in bone conduction. Audiograms of the father and the patient's sister were normal. None of the family members apart from the patient showed any deviation in eye measurements. Thus, we believe our patient represents a new mutation.

The association between Waardenburg syndrome and aganglionic megacolon (Hirschsprung disease) is well known. ${ }^{1}$ Atretic gastrointestinal anomalies have been described in association with the Waardenburg syndrome (table), but have never been considered part of the syndrome. Fisch ${ }^{3}$ was the first to describe a patient with Waardenburg syndrome and oesophageal atresia. In his article he mentions the possibility that such an anomaly may be the cause of death in a few other infants with the Waardenburg syndrome. Anal atresia observed in the Waardenburg syndrome has been described twice by Roux et at and Nutman et al. ${ }^{2}$ We present here a case of possible Waardenburg syndrome with anal atresia and oesophageal atresia.

Gastrointestinal atretic lesions can be traced to developmental arrest at various stages of maturation. ${ }^{7}$ Oesophageal atresia occurs in about 1 in 5000 children. Anal malformations are also relatively rare $(1$ in 10000$) .9$

Fraser ${ }^{10}$ estimates that 1 in 10000 people carries a gene that can cause the Waardenburg syndrome. Thus, the chance of random coincidence of oesophageal or anal atresia and Waardenburg syndrome would be expected to be less than 1 in 5 to $15 \times 10^{7}$ children and the association with both anal and oesophageal atresia even rarer. ${ }^{11}$ It is generally accepted that the Waardenburg gene interferes with neural crest cell migration as exhibited by its association with aganglionic megacolon. ${ }^{12}$ It is conceivable that this gene also disrupts cell migration of the gastrointestinal tract accounting for the various atretic lesions described.

TABLE Cases of the Waardenburg syndrome with associated gastrointestinal anomalies.

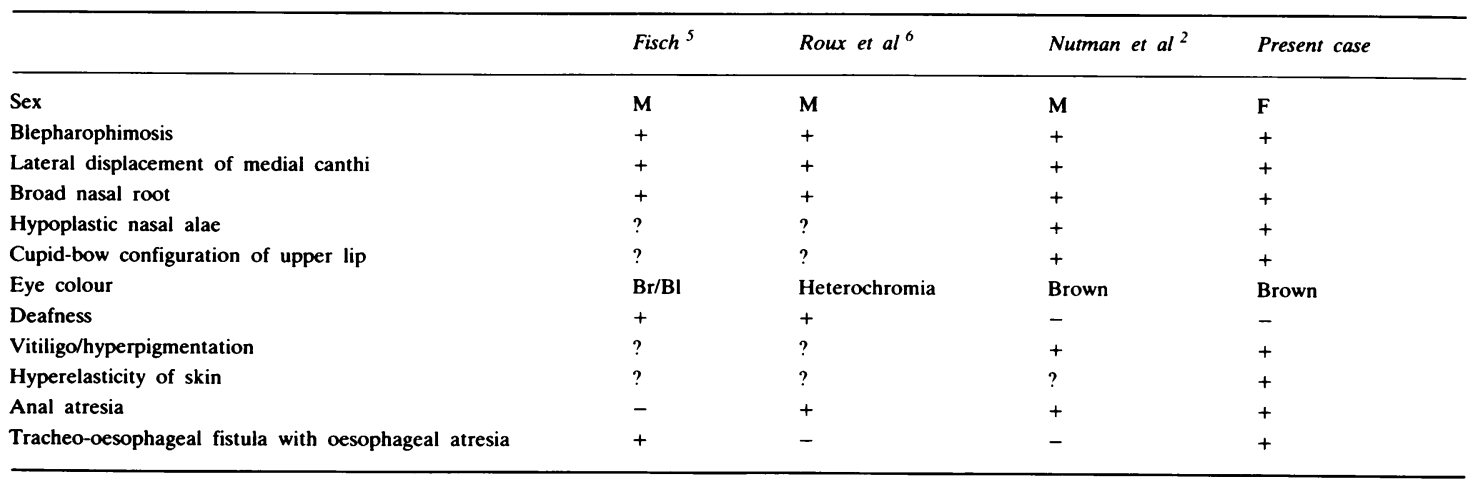


Thus, it seems likely that the association between atretic lesions of the gastrointestinal tract and the Waardenburg syndrome may be significant, but because of its rarity it has been overlooked.

The authors thank Professor David Klein from the Department of Ophthalmology, University of Geneva Medical School, for his helpful advice.

\footnotetext{
References

${ }^{1}$ Omenn GS, McKusick VA. The association of Waardenburg syndrome and Hirschsprung megacolon. Am J Med Genet 1979:3:217-23.

2 Nutman J, Nissenkorn I, Varsano I, Mimouni M, Goodman RM. Anal atresia and the Klein-Waardenburg syndrome. J Med Genet 1981;18:239-41.

${ }^{3}$ Feingold M, Bossert WH. Normal values for selected physical parameters: an aid to syndrome delineation. Birth Defects 1974;10:1-3.

${ }^{4}$ Goodman RM, Gorlin RJ. The malformed infant and child: an illustrated guide. New York: Oxford University Press, 1983: $422-3$.
}

${ }^{5}$ Fisch L. Deafness as part of a hereditary syndrome. $J$ Laryngol 1959;73:355-82.

6 Roux CH, Baheux G, Gaulier M, Caldera R, Soepardan L. Le syndrome de Waardenburg. Une observation familiale portant sur quatre generations et vingt-trois sujets. Ann Genet (Paris) 1970;13:125-8.

${ }^{7}$ Gray SW, Skandalakis JE. Embryology for surgeons. Philadelphia: Saunders, 1972:202-16.

${ }^{8}$ Ingalls TH, Prindle RA. Esophageal atresia with tracheoesophageal fistula: epidemiologic and teratogenic implications. $N$ Engl J Med 1949;240:987-95.

${ }^{9}$ Hasse W. Associated malformation with anal and rectal atresiae. Prog Pediatr Surg 1970;9:99-103.

${ }^{10}$ Fraser GR. The causes of profound deafness in childhood. Baltimore: Johns Hopkins University Press, 1976:90-132.

1 "Holder TM, Cloud DT, Lewis JE Jr, Pilling GP. Esophageal atresia and tracheoesophageal fistula. A survey of its members by the surgical section of the American Academy of Pediatrics. Pediatrics 1964;34:542-9.

12 Branski D, Dennis NR, Neale JM, Brooks LJ. Hirschsprung's disease and Waardenburg's syndrome. Pediatrics 1979;63:803-5.

Correspondence and requests for reprints to $\mathrm{Dr} \mathbf{R}$ Steinherz, Department of Pediatrics A, Beilinson Medical Center, Petah Tiqua 49 100, Israel.

\title{
Multifocal meningiomas in a patient with a constitutional ring chromosome 22
}

\author{
T ARINAMI*, I KONDO $\dagger$, H HAMAGUCHI $\dagger$, AND S NAKAJIMA* \\ From *Ibaraki Prefectural Colony, Higashiibaraki-gun 319-03; and the Department of Human Genetics, \\ Institute of Basic Medical Sciences, University of Tsukuba, Ibaraki-ken 305, Japan.
}

SUMMARY We report a patient with a constitutional ring chromosome 22 , in whom multifocal meningiomas were confirmed at necropsy, and discuss the relationship between the constitutional chromosome change and tumourigenesis of meningiomas in this patient.

There have been many reports of patients with partial monosomy of chromosome 22 , but the clinical features of a chromosome 22 monosomy syndrome have not been established. ${ }^{12}$ However, monosomy 22 and deletion of the distal end of the long arm of chromosome $22(22 \mathrm{q}-)$ are the commonly observed cytogenetic changes in cultured meningioma cells. ${ }^{3}$ There has been no report so far of meningiomas arising in patients with constitutional chromosome 22 anomalies.

\section{Case report}

The proband, an institutionalised mentally retarded

Received for publication 9 March 1985 Accepted for publication 19 March 1985. male, was found to have a ring chromosome 22 during a cytogenetic survey, which has been reported previously. ${ }^{4} \mathrm{He}$ was the second child of unrelated healthy parents and was born to a 32 year old father and 29 year old mother. A brother and a sister were healthy and of normal intelligence. He was delivered at term after an uneventful pregnancy, birth weight $2715 \mathrm{~g}$ and length $49 \mathrm{~cm}$. Chest and head circumferences were $28 \mathrm{~cm}$ and $30 \mathrm{~cm}$, respectively. Early development was slightly delayed and he began walking alone at 18 months. He suffered infantile tuberculosis at 2 years which was cured after treatment. His mental development was very retarded.

At the age of 20 , the proband was admitted to an institution because of an IQ of 21 . On examination, he was $158 \mathrm{~cm}$ tall $(-1.6 \mathrm{SD})$ and weighed 50 $\mathrm{kg}(-2.5 \mathrm{SD})$. His occipitofrontal circumference was $52 \mathrm{~cm}(-2.5 \mathrm{SD})$. His skull was microcephalic and dolichocephalic (cephalic index $0 \cdot 85$ ), with a flat occiput and cutis verticis gyrata. Secondary sexual development was normal. Cutaneous nodules and café-au-lait patches were not present. Other abnormalities noted were unusual facial appearance with 